excluded certain patients due to "safety concerns" (eg, bloodstream or respiratory infections, immunosuppression, others). ${ }^{10}$ What are the potential risks to subsequent patients from external device microbial contamination, including bloodborne pathogens? How frequently do other anesthesia departments that reuse bags and circuits disinfect them, what disinfection method is used, and what patients, if any, are excluded from having anesthesia with a reused circuit? Clearly, the FDA clearance did not consider external circuit contamination and cross contamination to subsequent patients. Why did SHEA not address this important issue?

\section{References}

1. Munoz-Price LS, Bowdle A, Johnston BL, et al. Infection prevention in the operating room anesthesia work area. Infect Control Hosp Epidemiol 2019;40:1-17.

2. Holroyd JL, et al. Universal intravenous access cleaning device fails to sterilize stopcocks. Anesth Analg 2014;118:333-343.

3. Loftus RW, Patel HM, Huysman BC, et al. Prevention of intravenous bacterial injection from health care provider hands: the importance of catheter design and handling. Anesth Analg 2012;115:1109-1119.

4. Loftus RW, Koff MD, Burchman CC, et al. Transmission of pathogenic bacterial organisms in the anesthesia work area. Anesthesiology 2008;109:399-407.
5. Loftus RW, Brindeiro BS, Kispert DP, et al. Reduction in intraoperative bacterial contamination of peripheral intravenous tubing through the use of a passive catheter care system. Anesth Analg 2012;115:1315-1323.

6. Yébenes JC, Vidaur L, Serra-Prat M, et al. Prevention of catheter-related bloodstream infection in critically ill patients using a disinfectable, needle-free connector: a randomized controlled trial. Am J Infect Control 2004;32:291-295.

7. Mahida N, Levi K, Kearns A, Snape S, Moppett I. Investigating the impact of clinical anaesthetic practice on bacterial contamination of intravenous fluids and drugs. J Hosp Infect 2015;90:70-74.

8. Guidelines for the prevention of intravascular catheter-related infections 2011. Centers for Disease Control and Prevention website. https://www .cdc.gov/infectioncontrol/guidelines/pdf/bsi/bsi-guidelines-H.pdf. Published 2011. Accessed February 21, 2019.

9. Birnbach DJ, Rosen LF, Fitzpatrick M, Carling P, Munoz-Price LS. The use of a novel technology to study dynamics of pathogen transmission in the operating room. Anesth Analg 2015;120:844-847.

10. Hübner NO, Daeschlein G, Lehmann C, et al. Microbiological safety and cost-effectiveness of weekly breathing circuit changes in combination with heat moisture exchange filters: a prospective longitudinal clinical survey. GMS Krankenhaushyg Interdiszip 2011;6(1):Doc15. doi: 10.3205/ dgkh000172.

\title{
Transmission routes of the virus causing viral hemorrhagic fever: Extreme precautions are prudent but high-quality evidence must be gathered
}

\author{
Takuya Yamagishi MD², Kensaku Kakimoto $\mathrm{PhD}^{2}$, Ikuko Doi BS², Chiaki Kawakami MD², \\ Tomoe Shimada MD ${ }^{1}$, Tamano Matsui MD ${ }^{1}$, Kazunori Oishi MD ${ }^{1}$ and Masayuki Saijo MD ${ }^{3}$ \\ ${ }^{1}$ Infectious Disease Surveillance Center, National Institute of Infectious Diseases, Tokyo, Japan, ${ }^{2}$ Field Epidemiology Training Program, National Institute of \\ Infectious Diseases, Tokyo, Japan and ${ }^{3}$ Department of Virology I, National Institute of Infectious Diseases, Tokyo, Japan
}

To the Editor-Moon et $\mathrm{al}^{1}$ reported that airborne precautions might be needed when dealing with fatal cases of severe fever with thrombocytopenia syndrome (SFTS). For diseases with high fatality rates that lack specific and effective treatment, it is prudent to take a more extreme prevention strategy than that based on the documented transmission route. ${ }^{2}$ One example in which this strategy is applied is Ebola virus disease, for which extreme precautions are taken. ${ }^{3}$ Given that SFTS virus (SFTSV) is a viral hemorrhagic fever virus that causes severe disease with a high fatality rate, we apply the same strategy to SFTS. Airborne precautions are recommended when healthcare providers conduct aerosolgenerating procedures such as endotracheal intubation on a patient suspected of having SFTSV.

The transmission route of the disease treated under this prevention strategy should also be carefully examined during each outbreak. To date, airborne transmission of naturally occurring hemorrhagic fever viruses has not been documented. ${ }^{2}$ The patient in the Moon et al article was a doctor wearing only a fluid-shield

Author for correspondence: Takuya Yamagishi, Email: tack-8@niid.go.jp

Cite this article: Yamagishi T, et al. (2019). Transmission routes of the virus causing viral hemorrhagic fever: Extreme precautions are prudent but high-quality evidence must be gathered. Infection Control \& Hospital Epidemiology, 40: 608-609, https://doi.org/10.1017/ ice. 2019.46 mask and gloves who performed endotracheal intubation on an SFTS patient and was infected with SFTS thereafter. Respiratory droplets are thought to be generated during endotracheal intubation, and protection of the eyes, nose, and mouth is recommended during the procedure in accordance with standard precautions. ${ }^{2}$ Because the doctor in the article did not protect his eyes, it was possible that he acquired SFTSV through droplet contact with his eyes during the intubation procedure. However, this observation does not provide any evidence that SFTSV infects people through airborne transmission.

It is crucial to improve the level of precautions taken in acutecare settings in SFTS-endemic areas to prevent SFTSV transmission because most of the nosocomial transmissions of SFTSV are thought to occur before the diagnosis of the patient (infector) is confirmed as SFTS by the laboratory. ${ }^{4-9}$ Standard precautions should be the norm for clinicians when they treat patients suspected of having SFTS. Between April 2013, when SFTS was designated as a notifiable disease in Japan, and December 2018, 400 cases have been reported in Japan. ${ }^{10}$ SFTS occurred sporadically in most patients, who were thought to have been infected with SFTSV through a tick bite during outdoor activities or by direct contact with a sick animal. To date, no case of healthcareassociated infection has been reported in Japan. However, we 
need to remain conscious of the risk of healthcare-associated infections.

We believe that strict adherence to standard and contact precautions can reduce the risk of nosocomial transmission of SFTSV and that taking airborne precautions as an extreme measure is required during aerosol-generating procedures. Additional evidence on the route of SFTSV transmission might guide the best precautions in the future.

Acknowledgements. We thank all the physicians and the staff at local public health centers and public health institutes who engage in surveillance activities in Japan.

Financial support. This report was funded by grants for the Research Program on Emerging and Re-emerging Infectious Diseases from the Japan Agency for Medical Research and Development.

Conflict of interest. All authors report no conflicts of interest relevant to this article.

\section{References}

1. Moon J, Lee H, Jeon JH, et al. Aerosol transmission of severe fever with thrombocytopenia syndrome virus during resuscitation. Infect Control Hosp Epidemiol 2019:238-241.
2. Siegel JD, Rhinehart E, Jackson M, Chiarello L. 2007 Guideline for isolation precautions: preventing transmission of infectious agents in health care settings. Am J Infect Control 2007;35:S65-S164.

3. World Health Organization. Personal protective equipment in the context of filovirus disease outbreak response: rapid advice guideline. World Health Organization website. https://apps.who.int/iris/handle/10665/ 251426. Published 2016. Accessed February 9, 2019.

4. Gai Z, Liang M, Zhang Y, et al. Person-to-person transmission of severe fever with thrombocytopenia syndrome bunyavirus through blood contact. Clin Infect Dis 2012;54:249-252.

5. Kim WY, Choi W, Park SW, et al. Nosocomial transmission of severe fever with thrombocytopenia syndrome in Korea. Clin Infect Dis 2015;60: 1681-1683.

6. Choi SJ, Park SW, Bae IG, et al. Severe fever with thrombocytopenia syndrome in South Korea, 2013-2015. PLoS Negl Trop Dis 2016;10: e0005264.

7. Shi J, Wang H, Huang D, et al. A cluster of symptomatic and asymptomatic infections of severe fever with thrombocytopenia syndrome caused by person-to-person transmission. Am J Trop Med Hyg 2017;97:396-402.

8. Gong Z, Gu S, Zhang Y, et al. Probable aerosol transmission of severe fever with thrombocytopenia syndrome virus in southeastern China. Clin Microbiol Infect 2015;21:1115-1120.

9. Jiang XL, Zhang S, Jiang M, et al. A cluster of person-to-person transmission cases caused by SFTS virus in Penglai, China. Clin Microbiol Infect 2015;21:274-279.

10. Severe fever with thrombocytopenia syndrome, Japan. Japanese National Institute of Infectious Diseases website. https://www.niid.go.jp/niid/ja/ sfts/3143-sfts.html [In Japanese.] Accessed February 9, 2019.

\title{
Practice and attitudes toward alcohol-based hand disinfection among German infection control teams
}

\author{
Sebastian Schulz-Stübner PD Dr. med. ${ }^{1}$, A Volkmann BA ${ }^{1}$, W Ebner Dr. med. ${ }^{2}$ and T Hauer Dr. med. ${ }^{1}$ \\ ${ }^{1}$ German Consulting Center for Infection Prevention and Control [Deutsches Beratungszentrum für Hygiene (BZH GmbH)], Freiburg, Germany and ${ }^{2}$ Institute for \\ Infection Prevention and Hospital Epidemiology, Medical Center, University of Freiburg, Freiburg, Germany
}

To the Editor-Recent publications have discussed the microbiological effectiveness of 15 seconds of alcohol-based hand disinfection and of reducing the time recommendations for alcohol-based hand disinfection in standard operating procedures to increase compliance, ${ }^{1}$ the reprocessing of conventional hand disinfection dispensers, ${ }^{2}$ and the technical failure rate of automatic hand disinfection dispensers, ${ }^{3}$ and the problems related to using alcoholcontaining tissue wipes rather than conventional dispensers. ${ }^{4}$

We designed an anonymous survey and distributed it during the 2018 Freiburg congress of infectious diseases and infection control (Freiburger Infektiologie- und Hygienekongress) to analyze the attitudes of German infection control teams regarding those issues and the integration of patients into hand disinfection programs.

\section{Material and Methods}

Congress participants were asked to deposit the filled out data sheets in exit-door drop boxes. Data were collected without personal

Author for correspondence: Dr Sebastian Schulz-Stübner, Email: Schulz-stuebner@bzhfreiburg.de

Cite this article: Schulz-Stübner S, et al. (2019). Practice and attitudes toward alcoholbased hand disinfection among German infection control teams. Infection Control \& Hospital Epidemiology, 40: 609-612, https://doi.org/10.1017/ice.2019.53 identifiers according to the EU General Data Protection Regulation (GDPR). Therefore this is not human research and the data analysis did not require the review of an institutional review board. Predefined subgroup analyses included nurse infection control practitioners (NICP) and physician members (PM) of the infection control team (either hygiene-link physicians or certified specialists in hospital hygiene). The Fisher exact test was used to test for significance between groups; $P<.05$ was considered statistically significant.

\section{Results}

In total, 385 surveys were returned (mean age, 50 years; range, 24-66). Of all respondents, $20 \%$ were from hospitals with $<200$ beds, $25 \%$ were from hospitals with $201-400$ beds, $18 \%$ were from hospitals with 401-600 beds, $19 \%$ were from hospitals with $>600$ beds, $13 \%$ were from rehabilitation hospitals, and $5 \%$ were from elsewhere ("other"). Among all respondents, 96 were in the PM group and 223 were in the NICP group; the remaining respondents were link nurses, public or occupational health physicians, and medical technicians. Table 1 shows the answers to the survey questions.

The only statistically significant difference $(P=.00001)$ between physician and nurse members of the infection control team was 